\section{TO WHAT FACTORS DO UNIVERSITY STUDENTS ATTRIBUTE THEIR ACADEMIC SUCCESS?}

\begin{abstract}
This study explores the attributions to which undergraduate university students ascribe academic achievement. Attribution theory was used as a means to understand scholastic success-failure. The questions that guided the study were the following: What are the causal attributions that predominate in students' academic achievement? Is there a difference between male and female students? Is there a difference if average grades and the number of failed subjects, factored as benchmarks of academic achievement, are considered? Do the measured attributions have any weight when predicting students' grades? A Likert scale measuring eight different attributions of academic achievement was applied to 165 students. The results showed that the most important attribution for academic achievement was intelligence. Sex-related differences were found in two attributes: calm and effort. In general, students with four failed subjects were those with the lowest averages measured in attributions. The variables that predicted good grades for male students were effort and good teachers, for female students, a liking for teachers, luck, and attention.
\end{abstract}

\section{KEYWORDS}

Academic achievement, causal attributions, effort, exit attribution, motivation for achievement

\section{HOW TO CITE}

García y García B. E. (2021) 'To What Factors do University Students Attribute Their Academic Success?', Journal on Efficiency and Responsibility in Education and Science, vol. 14, no. 1, pp. 1-8. http://dx.doi.org/10.7160/eriesj.2021.140101

\section{Blanca Elba García y García}

Business Faculty, Universidad La Salle, Mexico

blanca_elba@yahoo.com.mx

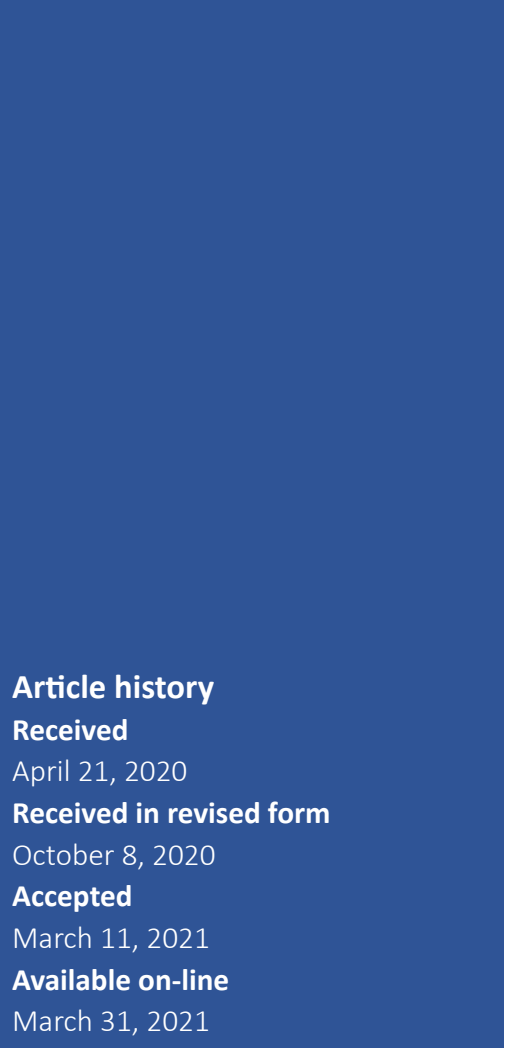

\title{
Highlights
}

- The study discusses the role of eight attributions to the academic success of university students and their relationship to academic achievement.

- Students perceived that intelligence, effort and attention are the most important attributions to academic success.

- Predictor attributional variables of grades by males and females are different.

\section{INTRODUCTION}

Much of the research that has been developed to understand the factors that determine academic achievement, analyze a wide variety of variables and theories, which do not directly consider the students' rationale about factors that lead them to success in their studies. This study aims to explore the success attributions that predominate among university students and their relationship to academic achievement. The basis of the study is the attributional theory originally set forth by Heider $(1944 ; 1958)$ and Weiner's works $(1985 ; 1972)$ on attribution and motivation for achievement. Essentially, this theory points out that people, in order to make sense of their lives, tend to seek cause-and-effect relationships in order to explain their own behavior, other people's and, in general, the events that surround them. Kelley (1967) proposes that people create causal schemes that are used to explain the phenomena around them and to make inferences take into account three conditions: the individual himself (internal attribution), the stimulus (external attribution) or the circumstances surrounding the fact.

Weiner $(1972,2010 b)$ based on Heider and Kelly's proposals tries to apply the attributional theory to understand the causes of success and failure related to academic achievement. It clarifies that this theory alludes to a phenomenon of subjective causality, it is not necessarily about finding the real causes of events. Attribution is a process of causal perception that varies by gender, age, context, group or culture, it is also different depending on whether attribution is made to one's own behavior or other people's (Digia and Zdravkovi, 2019; Weiner, 2010b). However, it is possible to observe that in certain contexts the same causes appear regularly, which allows us to understand with some degree of generality the origins that are attributed to events, this is applicable in the educational field.

In particular, the causes attributed to school success or failure on the part of both students and teachers are capacities, skills, 
intelligence, homework difficulty, teacher's characteristics, or luck (Weiner, 1985). Whatever the attribution, it will positively or negatively impact students' achievements and therefore their motivation, feelings, behavior, and school decisions. Hence the importance of understanding this process in educational environments and in particular from the perspective of students (Weiner, 2010a).

Finally, in order to understand the attributional styles of individuals and in particular students, it is important to consider at least three variables involved in the process of building causality schemes. The first is the recognition that the causes we identify in the facts, present a bias, that is, causal attribution is subjective, and according to Weiner (2010b) responds to a hedonic process. In this way, there is a tendency to derive internal causes of the behavior of others and external causes to their own. It is common to find that success will always be seen as a result of effort, an internal cause and failure due to external causes like luck. The second variable is related to the communications that students receive from their teachers, whether conscious or not, they make comments that can be used as explanations for school performance (Matteucci and Gosling, 2004). Finally, the third variable is the management of impressions that individuals make to manipulate the causal beliefs of others, using resources such as denying, making excuses, and seeking justifications, especially when school objectives are not achieved.

Weiner (2010a) notes that causal attributions have at least four characteristics:

- Locus or location. Considering Rotter's (1966) contributions to control locus, Weiner (2010a) notes that the causes of a fact can be perceived from within or outside the actor, can be made internal or external attributions. In this way, the one who makes external attributions to his achievements depends on the environment and the others. Conversely, those who make internal powers consider that the things that happen to them are the product of their own actions, trust their own resources and are able to transform their environment.

- Controllability. There are causes that the person can manage at will, unlike others beyond their control. If school failure is attributed to a lack of effort, then it is something that students will be able to control, instead if they attribute it to the characteristics of the teacher, they will hardly be able to control their success or failure.

- Stability. The cause may or may not be permanent in time. Intelligence is conceived as an ability that does not change throughout life, when failure is attributed to it, it will hardly be thought as something that we can change and therefore will always be wrong in studies.

- Globality. Causes can be generalized to a variety of situations. If luck is the attribution students recognize as the cause of their school failure, they are likely to use it to explain their stumbles in other contexts.

In this regard, Weiner (2010a) notes that these dimensions provide the meaning that students will use to explain their academic achievement. For example, he has found that controllable and temporarily stable attributions positively impact motivation for study, persistence and academic achievement, producing feelings of pride in students. In this same sense, Vélez (2007) points out that the meaning that students attribute to school success, will be used as a scheme that will guide their behavior in regard to their studies.

Based on these ideas, there are many researchers who have studied how these attributions work to explain the successfailure of students. Van Overwalle (1989), Batool and Akhter (2006), García (2006), Boruchovitch (2004), Kamal and Bener (2009), Lei (2009), Perry, Daniels, and Haynes (2008), Sucuoglu (2014), Smith and Skrbi (2017), and Munir (2020) who have explored attributions such as effort, difficulty of tasks, quality of teachers, attention, ability and luck, as determinants of academic success. All of them found that basically, effort and ability are the most frequently mentioned reasons as the reasons that lead to school success, and their main features are to be internal and controllable. Specifically, Batool and Akhter (2006), point out that external attributions such as luck or task difficulty, both external and uncontrollable, lead students to school failure.

More recently, Taskiran and Aydin (2018) in their study reinforce the trend of research in this regard, they find that controllable and unstable attributions, such as effort, teachers, motivation and class participation, are the most frequently leading to the success of those who learn a foreign language. Bouchaib, Ahmadou, and Abdelkader (2018) found that both successful and unsuccessful students noted that extrinsic attributions are important for academic achievement, however successful students also emphasized the role of internal attributions such as ability and effort.

There are studies that analyze the mediating role of school success-failure attributions in self-efficacy. Bandura (1986, 1997) defines the self-efficacy as the set of beliefs people have about their ability to achieve goals or face situations originated in their social media. Students' beliefs about their academic ability influence perseverance, persistence, performance, and self-regulation of learning; self-efficacy becomes a motivating force predictive of self-beliefs and academic performance (Pajares, 1996). Stajkovic and Summer (2006), and García-Fernandez et al. (2016) point out that selfefficacy and causal attribution are reciprocally related. When individuals have high levels of self-efficacy, they attribute their success to internal causes, they have a strong personal conviction on their skills in order to achieve their goals. Bouchaib, Ahmadou, and Abdelkader (2018) recognize the strength of students' beliefs in their skills to learn and achieve high levels of competence. For this reason, predictive capacity of academic self-efficacy perceived by students on high selfattributions, such as ability and effort, has been studied (Hsieh and Schallert, 2008; Lee, Song and Kim, 2018; Sáez et al., 2018). García-Fernández et al. (2016) studied this relationship in a sample of 874 Chilean teenage students. Regression analyses showed that academic self-efficacy was a predictor of self-attributions such as ability and effort.

A relationship has also been found between attributions and school anxiety. In this sense, Lagos et al. (2016) found that when attributions relate to external causes, high school students presented higher averages of anxiety. Also, when effort was 
recognized as a cause of success, high anxiety levels were present. Gonzálvez et al. (2018) found that students' rejection of mathematics was mediated by maladaptive attributions such as lack of ability and effort, as well as external causes. They conclude that such self-attributions do not promote learning and negatively affect academic development and self-confidence. Maymon et al. (2018) conducted a study with the intention of finding out whether positive emotions can be predicted from internal and controllable causal attributions, contrary to what stable attributions which can be predictive of negative emotions. Indeed, they found that stable and external attributions produce maladaptive emotions such as hopelessness, boredom, anxiety and guilt. On the other hand, external but controllable attributions produce fewer emotional problems, students find themselves more hopeful and less anxious. Finally, as hypothesized, the effects of stable attributions have negative effects on their emotions.

Gender comparisons have been another trend in studies on this issue. For example, Boruchovitch (2004) found that men, unlike women, attribute success in mathematics to intelligence and that they like their teachers. Rodríguez-Marín and Inglés (2011) found a very similar attribute profile between the genders, except because women believe success is due to ability and failure to lack of effort. Digia and Zdravkovi (2019) conducted a study to understand how attributional styles related to the way students faced exam situations, they found that while the men interpreted failure as a lack of ability, the women focused more on the problem in test situations and attribute success to their effort. These authors also claim that women have more functional attributions than men. This partially explains the obtained results, women may be directed towards greater effort, while men are directed towards developing abilities.

Based on the attributions used by Boruchovitch (2004) in her research with Brazilian students, the goal of this research is to find out the relationship between the causes that undergraduate students attribute to their academic achievement and school performance.

Thus, it is intended to answer the following questions:

- What are the causal attributions that predominate in the academic success of students?

- Is there any difference between men and women?

- Is there any difference considering the number of subjects failed as benchmarks of academic success?

- Do the measured attributions have any weight in predicting the grades obtained by students?

The following sections of the paper describe the measuring instrument that was applied to a group of university students and the forms of data processing. In the results section, the attribution patterns found in the sample are presented, comparisons are made by gender and failed subjects, finally presenting the weight of each attribution of success measured in the prediction of students' grades.

\section{MATERIALS AND METHODS Participants}

The sample based on a non-probability convenience sampling from three private universities in Mexico, consisted of 165 undergraduate students from various specialties. Of these, 74 were men and 91 women, with averages ranging from 6 to 10 grades; 65 of them had approved all their subjects throughout their school life and the rest had between 1 and 15 failed subjects.

\section{Measuring instrument}

For the design of the scale of successful attributions, the eight variables proposed by Boruchovitch (2004) were used. Hence, four internal causes (calm, effort, attention, intelligence) and four external causes (liking their teachers, easy tasks, good teachers, luck) were measured. Unlike multi-item scales, the instrument was built using a single-item technique; examples with this type of measurements can be found in studies such as Cheah et al. (2018), Fisher, Matthews and Gibbons (2015) and Diamantopoulos et al. (2012). The attributions were measured on a 10-point Likert scale at which each was evaluated globally and independently. However, considering that items all together measured success attributions, the item-total analysis used in Cronbach's reliability was applied in order to discard items that affect scale consistency. The results yielded moderate alpha values between.65 and.69, therefore any item was removed from the scale, because total reliability was not affected.

\section{Procedure}

The questionnaires were applied at three different private universities, in classrooms, or in the open spaces of their campuses. They were informed that the questionnaire was completely anonymous and if they were willing to answer it, it would be taken as their informed consent to be able to use the data in this study, always retaining anonymity.

\section{Data Analysis}

Different statistical processes were carried out to answer the research questions. A descriptive analysis was made in order to identify the predominant attributes in the sample based on the averages obtained and were represented on a bar chart. The $t$-test of mean contrasts was used to find differences by gender. The sample was also classified into three groups to identify differences considering the number of failed subjects by applying a simple classification variance analysis. Finally, a regression analysis of successive steps was used to know the weight of each attribution measured in predicting the students' grades.

\section{RESULTS}

- What are the causal attributions that predominate in students' academic success?

Table 1 shows the attributional pattern that characterized the students in the sample. As can be seen from the values of the averages, the study participants consider that all the reasons for success presented contribute to their academic performance. The lower mean corresponds to luck with a $M=$ 6.21 (on a scale of 1 to 10), although to a lesser degree than the others, it is still present among the reasons that favor school achievement, however it is a totally uncontrollable, unstable 
and external element in relation to the students' actions. The attribution with the highest mean is intelligence $(M=8.15)$, students point that it is an internal and stable aspect over time, however uncontrollable since they cannot change it at will, it is the one that most determines their academic achievement. It is also worth noting that effort $(M=7.42)$ and attention $(M=7.04)$, aspects that depend entirely on the student, yield high averages. Also, having good teachers $(M=7.18)$, a factor totally out of the students' hands, seem to be determinant in their success. The trends observed in the sample were corroborated with the t-test for one sample. The $t$ values were found to have fluctuated between 3.81 and 18.20 with $d f=119$ and $p<.000$; thus, all trends were significant.

\begin{tabular}{l|c|c}
\multicolumn{1}{c|}{ Attributions } & Mean & Std. Dev. \\
\hline Intelligence & 8.15 & 1.10 \\
\hline Effort & 7.42 & 2.33 \\
\hline Good teachers & 7.18 & 2.22 \\
\hline Attention & 7.04 & 2.42 \\
\hline Liking for teachers & 6.92 & 2.20 \\
\hline Calm & 6.87 & 2.46 \\
\hline Easy task & 6.59 & 2.40 \\
\hline Luck & 6.21 & 2.84 \\
\hline
\end{tabular}

Table 1: Causal attribution related to academic success, average values, 2018 (source: own calculation)

\section{- Is there a difference between men and women?}

Table 2 shows statistically significant differences between men and women, associated to both the calmness and the effort in their approach to academic work. It is men who give greater weight to calm in order to succeed. In regard to effort, the data is reversed, because it is women who consider the role of this aspect most important in their achievement. The remaining means are very similar in both genders, however, it is important to highlight the difference in attribution related to luck, because although it is not significant, women seem to assign greater weight than their men counterparts.

\begin{tabular}{|c|c|c|c|c|c|}
\hline \multirow{2}{*}{ Attributions } & \multicolumn{2}{|c|}{ Mean } & \multicolumn{2}{|c|}{ Std. Dev. } & \multirow{2}{*}{$t$} \\
\hline & M & w & $\mathbf{M}$ & w & \\
\hline \multicolumn{6}{|l|}{ Internal Calm } \\
\hline Calm & 7.23 & 6.37 & 2.38 & 2.47 & 1.911 \\
\hline Effort & 6.80 & 7.79 & 2.78 & 1.90 & -2.342 \\
\hline Intelligence & 8.25 & 8.08 & 2.15 & 1.70 & .440 \\
\hline Attention & 6.86 & 7.17 & 2.60 & 2.30 & -.680 \\
\hline \multicolumn{6}{|l|}{ External } \\
\hline Easy task & 6.82 & 6.43 & 2.40 & 2.41 & .870 \\
\hline Good teachers & 6.60 & 6.89 & 2.11 & 2.30 & -.700 \\
\hline Liking for teachers & 6.31 & 6.75 & 1.99 & 2.34 & -1.100 \\
\hline Luck & 6.43 & 5.66 & 2.85 & 2.76 & 1.460 \\
\hline
\end{tabular}

${ }^{1} p=.05 ;{ }^{2} p=.03$

Table 2: Attributions to success by gender, 2018 (source: own calculation)
- Is there any difference considering the number of failed subjects as benchmarks of academic success?

To answer this question, the failed subjects were classified as shown in Table 3 and contrasts were made with a simple classification variance analysis. Before describing the results, it is worth noting that most students, $61 \%$, have failed among one and more than four subjects throughout their academic history and, in general, these have the lowest mean values in the measured attributions, the reasons for success explored in this study, are less important to them in contrast to the other two groups (without failing subjects or with 1 to 3 subjects noted).

The first observed statistically significant difference is associated with effort, the higher the number of failed subjects, yields a decrease in the mean. In Table 3 we can see that the averages decrease from 8.06 to 6.19 , students who fail more subjects consider that effort has less impact on the success of their studies. However, the average is 6.19 on a scale of 1 to 10 , that is, they are somehow aware of the role of effort in studies.

Another important difference is in attention, students with more failed subjects think this aspect is less important in their academic results. The same is true of the attribution related to teachers (Table 3), especially in the liking of teachers, it is observed that students with 1 to 3 failed subjects are those who have the highest means, followed of who have not failed any subject and finally, the students with four or more failed subjects have minor mean. It is worth highlighting the role of luck as a success factor, it increases slightly as the students have more subjects failed, this small difference was statistically significant.

- Do the measured attributions have any weight in predicting the grades obtained by students?

A regression analysis of successive steps was applied to answer this question, with the intention of finding the number of variables that would allow the best fit in predicting and obtaining a regression equation based on statistical criteria. Two different analyses were run, one for males and one for females. Tables 4 and 5 show the results obtained from the regression equations of academic success for each case. As observed, the attributions that predict grades are different in both genders.

Table 4 presents the regression results of males, it shows that effort $(b=.46)$ and good teachers $(b=.32)$ are the two variables that predict the averages of grades earned by students in their subjects, the six remaining variables did not enter the equation. Consequently, as students strive in their studies and consider having good teachers, they will most likely achieve high grades. The coefficients $b$ featured in the variables are high and significant $(t=3.88$ with $p=.001$ and $t=2.68$ with $p=.01$, respectively). In case of women, the three variables that had the best fit in the regression equation were, the liking for teachers $(b=.38)$, luck $(b=-.23)$ and the third variable was attention $(b=.22)$. All $b$ are statistically significant $t=3.41$ with $p=.001$, $t=2.09$ with $p=.04$ and $t=2.01$ with $p=.04$ (Table 5). 


\begin{tabular}{|c|c|c|c|c|}
\hline \multirow{2}{*}{ Attributions } & \multicolumn{3}{|c|}{ Failed subjects } & \multirow{2}{*}{$\boldsymbol{F}$} \\
\hline & None & 1 to 3 & 4 or more & \\
\hline \multicolumn{5}{|l|}{ Internal } \\
\hline Calm & 7.02 & 6.43 & 6.66 & .550 \\
\hline Effort & 8.06 & 7.93 & 6.19 & 9.511 \\
\hline Intelligence & 7.86 & 8.46 & 8.23 & .990 \\
\hline Attention & 7.63 & 7.65 & 5.92 & 7.542 \\
\hline \multicolumn{5}{|l|}{ External } \\
\hline Easy task & 6.80 & 6.90 & 6.14 & 1.180 \\
\hline Good teachers & 7.28 & 7.31 & 5.80 & 6.693 \\
\hline Liking for teachers & 6.84 & 7.43 & 5.59 & 7.712 \\
\hline Luck & 5.15 & 6.56 & 6.47 & 3.384 \\
\hline
\end{tabular}

${ }^{1} p<.001 ;{ }^{2} p=.001 ;{ }^{3} p=.002 ;{ }^{4} p=.03$

Table 3: Means obtained by number of failed subjects, 2018 (source: own calculation)

\begin{tabular}{l|c|c|c|c|c}
\multicolumn{1}{c|}{ Attributions } & \multicolumn{2}{|c|}{ Unstandardized coefficients } & Standardized coefficients & $\boldsymbol{t}$ & $\boldsymbol{p}$ \\
\hline Effort & $\boldsymbol{B}$ & Std. Error & $\boldsymbol{b}$ & .61 & 5.50 \\
\hline Good teachers & .22 & .04 & .32 & 2.68 & .001 \\
\hline
\end{tabular}

$R=.68, R^{2}=.46, F=20.66, p<.001$

Table 4: Men's regression equation, 2018 (source: own calculation)

\begin{tabular}{|c|c|c|c|c|c|}
\hline \multirow{2}{*}{ Attributions } & \multicolumn{2}{|c|}{ Unstandardized coefficients } & \multirow{2}{*}{$\begin{array}{c}\text { Standardized coefficients } \\
\text { b }\end{array}$} & \multirow{2}{*}{$\boldsymbol{t}$} & \multirow{2}{*}{$p$} \\
\hline & B & Std. Error & & & \\
\hline Liking of teachers & .10 & .03 & .38 & 3.41 & .001 \\
\hline Luck & .05 & .02 & -.23 & -2.09 & .040 \\
\hline Attention & .06 & .03 & .22 & 2.01 & .040 \\
\hline
\end{tabular}

$R=.49, R^{2}=.24, F=6.98, p<.001$

Table 5: Women's regression equation, 2018 (source: own calculation)

\section{DISCUSSION}

The objective of this research was to find the relationship between the causes that undergraduate students attribute to their academic achievement and school performance. Participants, while considering that all the causes explored as contributors to their achievement in school, particularly point to an attributional pattern characterized by four main reasons: intelligence, effort, good teachers and attention, which are the most frequently found in literature. Such attributions are considered by some authors as functional causes that contribute favorably to the school performance (Taskiran and Aydin, 2018; Bouchaib, Ahmadou and Abdelkader, 2018; Weiner, 2010b; Boruchovitch, 2004; Kamal and Bener, 2009). These two attributions characterized by being internal and controllable, are functional or adaptive since they allow academic achievement and lead to positive emotions (e.g. feeling proud of themselves), with favorable consequences on school performance (Weiner, 2010a; Maymon et al., 2018). It is these attributions that lead students to self-efficacy in their studies (García-Fernández et al., 2016).

The instability of these attributions is likely to make students aware that they may have some kind of control over them and put them at stake to achieve the goals that are proposed. They are attributions that will always accompany them and help them make decisions that will reinforce their self-esteem and motivation for achievement (Weiner, 1985), that is, they will be taken as a cognitive scheme that will determine their future behavior. As the school context fosters and supports these reasons for academic success, students will achieve better performance.

The attribution with the highest mean was intelligence, a cause that is not controllable, but is stable and internal. One tends to think that we are all born with a level of intelligence that does not change in time, hence its stability. In this sense, it can be said that if it is used as a source of positive academic results, those who consider having low intelligence, will surely think that they will not be able to face academic challenges. That is, intelligence can become a dysfunctional attribution of academic achievement and therefore not contribute to good performance in students. Fortunately, this idea can be refuted with Gardner's educational work (1993) on multiple intelligences, which points to the existence of various potentialities that humans can develop and employ in various situations. Even Feuerstein's proposal (e.g. Feuerstein et al., 1984) on cognitive modifiability, opens up the possibility that intelligence could be transformed like other abilities, he rejects the idea that it will be fully fixed throughout life. He claims that any individual is able to improve their intellectual capacity and learn through pedagogical experiences mediated by a docent. 
Maymon et al. (2018) point out that stable attributions, just because they cannot be changed, generate negative feelings. In this sense, intelligence becomes a dysfunctional attribution, for something that remains the same over time will always interfere with learning. Explaining school failure through this attribution can lead students to feel hopelessness, boredom, anxiety, and guilt (Maymon et al., 2018). Moreover, if one factors the global aspect of the attributions, intelligence can become the explanation for achievements or failures in other contexts.

So, it is recommended to address this aspect in the tutoring and orientations that take place across schools, directing students towards more functional causes to increase their performance, for instance, effort and persistence. Particularly this would have to be addressed to students who have low academic achievement, because from the data of this research for them, intelligence is one of the important attributions in their school performance.

Despite the fact, that effort presents one of the highest means, those who fail more school subjects consider that effort has less impact on the success of their studies. The difference between those who have failed subjects and the rest of the students is almost two points. That is, for underperforming students this attribution is less important, although the average size is above the midpoint of the scale, they are somehow aware of the role of effort in education.

As already noted, having good teachers, is among the four attributions found with the highest means in this study; it is an external attribution, unstable and uncontrollable, that appears in various investigations (e.g. Boruchovitch, 2004). It is a very recurrent explanation in students' positive school performance, however, given its peculiarities in some cases it could be a dysfunctional attribution to explain academic failure, especially if it is recurrent. While it is true that a good teacher can contribute to the academic achievement of a student, also, in some cases, as Matteucci and Gosling (2004) point out, it could be used as a resource to make excuses and seek justifications for poor performance.

The lowest mean found in attributions corresponds to luck, although to a lesser extent than the others, it is still present among the reasons that favor academic achievement. We could say that this totally uncontrollable, unstable and external element in the actions of students, is a dysfunctional attribution, which insufficiently contributes to their scholastic achievement, nonetheless it is recurrent in their discourse to justify high or low performance.

As for gender contrasts, our findings are aligned with the trends in a number of research studies, in that virtually, differences do not exist, men and women seem to have the same pattern of response (Boruchovitch, 2004; Rodríguez-Marín and Inglés, 2011). We can conclude that, with the exception of calm to execute the academic work, as well as effort, both genders attributed equal importance to the other reasons measured for academic success. For men, calm is more important than for women. It seems that in the academic achievement work frame women assign less importance to this aspect, in comparison to effort. They perceive that the latter is an important condition for achieving scholastic success. As Digia and Zdravkovi (2019) point out, these differences are likely to relate to the parenting habits that characterize women's education unlike men.

Finally, the applied regression analysis yielded two differential patterns between men and women. In males, effort (internal cause) and good teachers (external cause), are the grades predictors, so as they actively engage in their studies and are accompanied by a good teacher, their performance will be successful. Effort, a functional attribution, carries the greatest weight in prediction, it corresponds to an internal, and controllable aspect, which leads the student to be aware that much of his accomplishments depend on him. The second attribution, good teachers, carries a lower weight in prediction, in that it corresponds to an external and uncontrollable cause. This way, we can conclude that the male students in this study attribute their academic success greatly to their responsibility and commitment, but it will also rely on having good teachers. In women, three predictor causes were found, the first one has to do with the liking of teachers, an internal attribution, controllable and unstable, which is also the one that has the most weight in academic achievement among the members of this sample. This implies that if they perceive that a teacher is not to their liking, they will probably have difficulties in their subject matter. The second cause, luck, was considered a cause of success, they believe their studies depends on fortuitous factors and beyond their control. These two attributions can become dysfunctional and of little help in improving academic performance. The third variable that entered the regression equation was attention, an internal cause, controllable but unstable, that can be directly handled and that has a positive impact on their achievement. As we see in women, two predictors of academic success could be characterized as dysfunctional, because they are not controllable, they will offer inadequate help in their performance.

\section{CONCLUSION}

From the results of this study, we can derive that participants attribute their academic success to both internal and external causes, some of them can control and use them intentionally to improve their school performance, others depend on context such as assignments and teachers, or fortuitous elements such as luck. The interesting facts about the data presented is that none of the attributions presented averaged below 5, the averages exceeded 6 points; they all are important to the students of the sample and perceived as reasons to explain their school performance. In other words, although the reasons presented in this study are not the only ones in existence to achieve scholastic success or failure, study participants will resort to them, when they think they owe their achievements to any of them. The point is that some of these attributes can be considered dysfunctional, e.g. luck, or difficult to manage as students liking of teachers or difficulty with homework.

This work represents an exploratory approach to what students consider important for achieving good results in their studies. This line of work will allow developing educational intervention strategies with students, as well as teachers and tutors, based on the conceptions of the students themselves. In such way, considering the perspective of students, we will be able to understand how self-attributions can affect their performance 
and help them build functional attribution schemes that change their reasoning behind academic success in order to increase their motivation. It is important to remember that these schemes or attributions will have a positive impact to their study motivation, persistence, and achievement, resulting in feelings of pride that will help them maintain interest in school. The meaning that students attribute to school success will be used as a scheme that will guide their behavior to academic work. As can be seen, this research reinforces the idea that the teaching-learning process, not only depends on cognitive variables; the motivational and affective aspects are intimately linked to this process, so its analysis shows a more complete view of the complexities of school performance challenges.
In the future, it will be important to compare the findings with students at public universities. It is hypothesized that their attributional patterns of success are different, depending on the social and cultural contexts of their places of origin, and the visions that characterize public and private education. Contrasts could be made between undergraduate students and graduates, signatures, or fields of study. Other research paths to explore are variables of extrinsic-relational attributions such as teacher support, family, friends, or the school's organizational structure. Finally, it is recommended to make convergence validity assessments with multi-item instruments of scholastic causality attributions, to reinforce the use of measurements using a single item.

\section{REFERENCES}

Bandura, A. (1997) Self-efficacy: the exercise of control, New York: W.H. Freeman.

Bandura, A. (1986) Social foundations of thought and action: A social cognitive theory, Englewood Cliffs, New Jersey: Prentice-Hall.

Batool, S. and Akhter, T. (2006) 'Causal attribution patterns mainstream school students and their effect on achievement', FWU Journal of Social Science, Vol. 6, No. 2, pp. 131-134. https://doi.org/10.1155/2019/1950753

Boruchovitch, E. (2004) 'A study of causal attributions for success and failure in mathematics among brazilian students', Interamerican Journal of Psychology, Vol. 38, No. 1, pp. 53-60. https://doi. org/10.30849/rip/ijp.v38i1.841

Bouchaib, B., Ahmadou, B., and Abdelkader, S. (2018) 'High School Students Attributions of success in English Language Learning', International Journal of Instruction, Vol. 11., No. 2, pp. 89-102. https://doi.org/10.12973/iji.2018.1127a

Cheah, J. H., Sarstedt, M., Ringle, C. M., Ramayah, T. and Ting, H. (2018) 'Convergent validity assessment of formatively measured constructs in PLS-SEM: On using single-item versus multiitem measures in redundancy analyses', International Journal of Contemporary Hospitality Management, Vol. 30, No. 11, pp. 3192-3210. https://doi.org/10.1108/IJCHM-10-2017-0649

Diamantopoulos, A., Sarstedt, M., Fuchs, C., Wilczynski, P. and Kaiser, S. (2012) 'Guidelines for choosing between multi-item and single-item scales for construct measurement: a predictive validity perspective', Journal of Academic Marketing Science, Vol. 40, No. 3, pp. 434-449. https://doi.org/10.1007/s11747-011$\underline{0300-3}$

Digia, G. and Zdravkovi, M. (2019) 'Attributions to academic success and failure and the strategies for dealing with the examination situation as predictors of academic success', Philosophy, Sociology, Psychology and History, Vol. 18, No 2, pp. 67-80. https://doi.org/10.22190/FUPSPH1902067D

Fisher, G. G., Matthews, R. A. and Gibbons, A. M. (2015) 'Developing and investigating the use of single-item measures in organizational research', Journal of Occupational Health Psychology, Vol. 21, No. 1, pp. 3-23. https://dx.doi.org/10.1037/ a0039139

Feuerstein, R., Jensen, M., Rand, Y. and Hoffman, M. (1984) 'Instrumental Enrichment: An intervention program for structural cognitive modifiability', in Segal, J., Chipman, S. and Glaser, R. (ed.), Thinking and learning skills, Vol. 1, Hillsdale, New Jersey: Erlbaum.
García-Fernández, J. M., Inglés-Saura, C. J., Vincent, M., Gonzálvez C., Lagos, N. and Pérez-Sánchez, A. M. (2016) 'Relación entre autoeficacia y autoatribuciones académicas en estudiantes chilenos [Relationship between self-efficacy and academic selfattributions in Chilean students]', Universitas Psychologica, Vol. 5, No. 1, pp. 79-88. https://dx.doi.org/10.11144/Javeriana. upsy15-1.raaa

García, J. L. (2006) ‘Aportaciones de la teoría de las atribuciones causales a la comprensión de la motivación para el rendimiento escolar [Contributions from the theory of causal attribution to understanding motivation for school performance]', Ensayos, Vol. 21, pp. 217-232.

Gardner, H. (1993) Las inteligencias múltiples [The Multiple intelligencies], Madrid: Paidós.

Gonzálvez C., Sanmartín R., Vicent M., Inglés C. J., Aparicio-Flores M. P. and García-Fernández J. M. (2018) 'Academic selfattributions for success and failure in mathematics and school refusal', Psychology in the Schools, Vol. 55, No. 4, pp. 366-376. https://doi.org/10.1002/pits.22117

Hsieh, P. H. P., and Schallert, D. L. (2008) 'Implications from self-efficacy and attribution theories for an understanding of undergraduates' motivation in a foreign language course', Contemporary Educational Psychology, Vol. 33, No. 4, pp. 513532. https://doi.org/10.1016/j.cedpsych.2008.01.003

Heider, F. (1958) The psychology of interpersonal relations, New York: Wiley.

Heider, F. (1944) 'Social perception and phenomenal causality', Psychological Review, Vol. 51, No. 6, pp. 358-374. https://doi. org $/ 10.1037 / \mathrm{h} 0055425$

Kamal, M. and Bener, A. (2009) 'Factors contributing to school failure among school children in very fast developing Arabian society', Oman Medical Journal, Vol. 24, No. 3, pp. 212-217. https://dx.doi.org/10.5001/omj.2009.42

Kelley, H. H. (1967) 'Attribution theory in social psychology', in Levine, D. (ed.), Nebraska Symposium on Motivation, Vol. 15, pp. 192-238. Lincoln: University of Nebraska Press.

Lagos, N., Inglés, C., Ossa C., Gonzálvez-Maciá, C., Vicent, M. and García-Fernández, J. (2016) 'Relación entre atribuciones de éxito y fracaso académico y ansiedad escolar en estudiantes chilenos de educación secundaria. [Relationship between academic success and failure and school anxiety in Chilean high school students]', Psicología desde el Caribe, Vol. 33, No. 2, pp. 146-157. https:// dx.doi.org/10.14482/psdc.33.2.7296 
Lee, J., Song, K. and Kim, D. (2018) 'Self-efficacy, attribution, and adjustment to college life', North American Journal of Psychology, Vol. 20, No. 3, pp. 575-600.

Lei, C. (2009) 'On the causal attributions of academic achievement in college students', Asian Social Science, Vol. 5, No. 8, pp. 87-96. https://dx.doi.org/10.5539/ass.v5n8p87

Matteucci, M. A. and Gosling, P. (2004) 'Italian and French teachers faced with pupil's academic failure: The norm of effort', European Journal of Psychology of Education, Vol. 19, No. 2, pp. 147-166. https://dx.doi.org/10.1007/BF03173229

Maymon R., Hall N. C., Goetz, T., Chiarella, A. and Rahimi, S. (2018) 'Technology, attributions, and emotions in post-secondary education: An application of Weiner's attribution theory to academic computing problems', PLoS ONE, Vol. 13, No. 3, pp. 1-36. https://doi.org/10.1371/journal.pone.0193443

Munir, T. (2020) 'Gender differences in attribution to success and failure in exams: students' perspectives', Pak Armed Forces Medicine Journal, Vol. 70, No. 2, pp. 437-441.

Pajares, F. (1996) 'Self-Efficacy Beliefs in Academic Settings', Review of Educational Research, Vol. 66, No. 4, pp. 543-578. https://doi.org/10.3102/00346543066004543

Perry, R. P., Daniels, L. M. and Haynes, T. L. (2008) 'Attributional (explanatory) thinking about failure in new achievement settings', European Journal of Psychology of Education, Vol. 24, No. 4, pp. 459-475. https://doi.org/10.1007/BF03172753

Rodríguez-Marín, J. and Inglés, C. J. (2011) 'Diferencias de sexo y curso en autoatribuciones académicas de estudiantes universitarios [Differences in sex and course in academic self-attributions of college students]', Revista Mexicana de Psicología, Vol. 28, No. 2, pp. 173-181.

Rotter, J. (1966) 'Generalized expectancies for internal versus external control of reinforcement', Psychological Monographs, Vol. 80, No. 1, pp. 1-28. https://doi.org/10.1037/h0092976

Sáez F. M., Bustos, C. E., Pérez, M. V., Mella, J. A., Lobos, K. A. and Díaz, A. E. (2018) 'Disposición al estudio, autoeficacia y atribuciones causales en estudiantes universitarios chilenos [Willingness to study, self-efficacy and causal attributions in Chilean university students]', Propósitos y Representaciones, Vol. 6, No. 1, pp. 199-245. https:// dx.doi.org/10.20511/pyr2018.v6n1.179
Stajkovic, A. D. and Summer, S. M. (2006) 'Self-efficacy and causal attributions: Direct and reciprocal link', Journal of Applied Social Psychology, Vol 30, No. 4, pp. 707-737. https://doi. org/10.1111/j.1559-1816.2000.tb02820.x

Smith, J. F. and Skrbi, Z. (2017) 'A social inequality of motivation? The relationship between beliefs about academic success and young people's educational attainment', British Educational Research Journal, Vol. 43, No. 3, pp. 441-465. https://doi. org/10.1002/berj.3272

Sucuoglu, H. (2014) 'Construct validity of success/failure attribution scale among Turkish university students', Educational Research and Reviews, Vol. 9, No. 11, pp. 326-339. https://doi. org/10.5897/ERR2014.1768

Taskiran, A. and Aydin, B. (2018) 'Do adult english language learners and their teachers have similar approaches to success?', Journal on Efficiency and Responsibility in Education and Science, Vol. 11, No. 1, pp. 1-8. https://doi.org/10.7160/eriesj.2018.110101

Van Overwalle, F. (1989) 'Structure of freshmen's causal attributions for exam performance', Journal of Educational Psychology, Vol. 81, No. 3, pp. 400-407. https://doi.org/10.1037/0022$\underline{0663.81 .3 .400}$

Vélez, T. I. (2007) 'Éxito escolar en el nivel medio superior: una mirada desde los jóvenes [School success at the upper middle level: A look of young people]', Tiempo de Educar, Vol. 8, No. 16, pp. 245-273.

Weiner, B. (2010a) 'The development of an attribution-based theory of motivation: A history of ideas', Educational Psychologist, Vol. 45, No. 1, pp. 28-36. https://dx.doi.org/10.5296/ijl. v4i2.1451

Weiner, B. (2010b) 'Attribution theory', International Encyclopedia of Education, Vol. 6, No. 6, pp. 558-563. https://doi. org/10.1002/9780470479216.corpsy0098

Weiner, B. (1985) 'An attributional theory of achievement motivation and emotion', Psychological Review, Vol. 92, No. 4, pp. 548-573. https://doi.org/10.3102/00346543042002203

Weiner, B. (1972) 'Attribution theory, achievement motivation, and the educational process', Review of Educational Review, Vol. 42, No. 2, pp. 203-215. https://doi. org/10.3102/00346543042002203 